\title{
A Case Report of Follicular Cholecystitis with Review of Literature
}

\author{
Dr. Bhavna Valecha*, Dr. Hemlata Kamra \\ Resident, Department of Pathology, BPS GMC for Women, Khanpur Kalan, Sonepat, Haryana, India
}

\author{
DOI: $10.36348 /$ sipm.2019.v04i11.009 \\ | Received: 18.11.2019| Accepted: 25.11.2019 | Published: 28.11.2019 \\ *Corresponding author: Dr. Bhavna Valecha
}

Abstract

Introduction: Follicular hyperplasia of the gall bladder is an extremely rare and benign entity characterized by hyperplastic lymphoid follicle with germinal center consisting of the lymphoid population. The lymphoid hyperplasia of the gallbladder is a rare condition, which can be diagnosed only by performing a histological examination. Here, we present the case of a 36-year-old woman with complaints of repeatable pain in the area of the right hypochondrium for a few months. Ultrasonography revealed chronic cholecystitis with a concrement in the lumen. Methods and Materials: We were reported a rare case of follicular hyperplasia of gall bladder in a 36 yrs old female presented into the department of surgery with a right side upper abdomen pain then she was diagnosed as cholecystitis and managed by cholecystectomy and specimen was received and processed for histopathological examination. Results: Due to chronic cholecystitis patient present with right upper abdominal pain and upon histopathological examination diagnosed incidently as follicular cholecystitis. Conclusion: Histopathological examination reveals a rare case of follicular cholecystitis A cholecystectomy was then performed. Histology shows nests of cells with lymphoid origin in the lamina propria, a multitude of lymphoid follicles and areas with pyloric metaplasia in the gallbladder wall. The case presented herein is of reactive lymphoid hyperplasia resembling a lymphoma combined with chronic cholecystitis, pyloric metaplasia, and cholelithiasis.

Keywords: Chronic cholecystitis, lymphoid hyperplasia, Lymphoma.

Copyright @ 2019: This is an open-access article distributed under the terms of the Creative Commons Attribution license which permits unrestricted use, distribution, and reproduction in any medium for non-commercial use (NonCommercial, or CC-BY-NC) provided the original author and sources are credited.

\section{INTRODUCTION}

Gall Bladder diseases are a significant cause of morbidity and mortality. Diseases affecting the gall bladder comprise a wide spectrum of diseases including nonspecific inflammatory diseases, acute \& chronic cholecystitis, granulomatous cholecystitis, follicular cholecystitis, gall bladder polyp, carcinoma pseudolymphoma. Follicular Cholecystitis is a condition in which there is a formation of numerous prominent lymphoid follicles in lamina propria throughout the gall bladder, creating a pseudolymphoma pattern. Follicle can be present throughout, the wall but most commonly seen in mucosal layer.

Lymphoid hyperplasia is a rare but benign lesion. Histologically, it comprises hyperplastic lymphoid follicles with germinal centers. It can occur in the lungs, the gastrointestinal tract (GIT), the orbit and the skin [1,2]. The lymphoid hyperplasia in the mucosa and the gallbladder wall is an extremely rare kind of lesion. Chronic inflammation or an autoimmune reaction are considered to be the pathogenic basis for the development of this condition [3]. There have been several reported cases of lymphoid hyperplasia with chronic cholecystitis not exceeding $2 \%$ of the cholecystectomies $[4,5]$

\section{CASE REPORT}

A 36 years old female patient presented to the department of surgery with chief complaints of right sided abdominal pain. She was managed conservatively. She had similar complain again after 4 months. On clinical examination, there was an absence of icterus. The vitals were stable. On palpation, there was a pain in the right hypochondrium and Murphy's sign was positive. On further investigations, total bilirubin level was $6.8 \mu \mathrm{mol} / \mathrm{l}$ and direct bilirubin was $1.7 \mu \mathrm{mol} / \mathrm{l}$. Other biochemical tests like alpha-amylase, aspartate aminotransferase (AST), alanine aminotransaminase (ALT), electrolytes and other were in the normal range. The hematological parameters were within normal values with the exception of a lightly accelerated erythrocyte sedimentation rate (ESR).Then she was diagnosed as cholecystitis and managed surgically by cholecystectomy. The specimen was received in the department of pathology for histopathological examination. 
Gross feature- Cholecystectomy specimen was measuring $5.3 \times 2.5 \mathrm{~cm}$. The outer surface is smooth and shiny with multiple fibrofatty adhesions. On cut section inner surface shows Bile stained velvety mucosa, wall thickness varies from $0.3-0.4 \mathrm{~cm}$ i.e. Gall bladder wall was thickened and gall stone was present in the lumen.

Microscopy- the Hematoxylin $(\mathrm{H})$ and Eosin (E) stained section from the gall bladder showed features of chronic cholecystitis with Rokitansky Aschoff Sinuses formation at places. Underlying lamina propria shows proliferating or reactive lymphoid follicles along with chronic inflammatory infiltrate comprising of lymphocytes, macrophages, and plasma cells. There was no necrosis and giant cell. There were more than three reactive lymphoid follicles found in a
$1 \mathrm{~cm} 2$ areas. Pathological diagnosis of follicular cholecystitis of gall bladder was made on the basis of above mentioned findings. Again Zeihl Neelson stain for tuberculosis and periodic acid Schiff for fungal etiology was also done and both were negative indicating not association with a specific agent.

Infiltration was mainly present in the lamina propria with chronic inflammatory monomorphic cells. - Lymphocytes, macrophages, and plasmocytes. There was a presence of numerous reactive lymphoid follicles with germinal centers. The presence of round cellular lymphoid infiltration and multitude lymphoid follicles therein eliminated the possibility of the lymphoproliferative lesion.

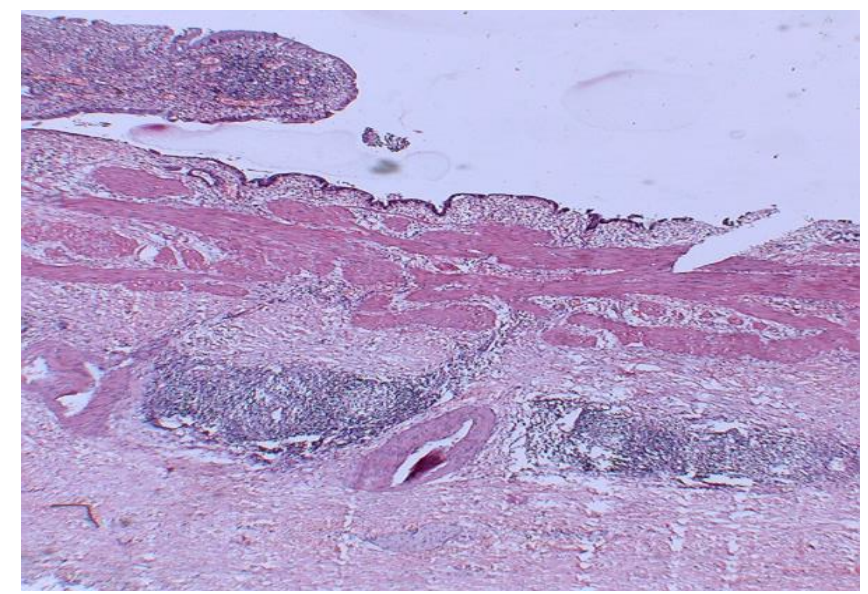

Photomicrograph 1- Prominent Lymphoid Follicles In The Lamina Propria 100x, H\&E

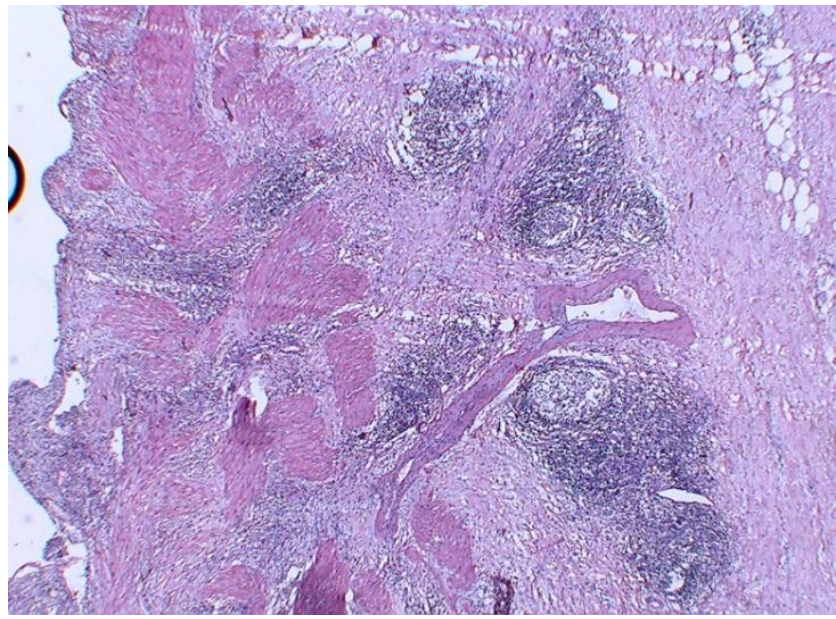

Photomicrograph 2- Follicular Cholecystitis 100x,H\&E

\section{DISCUSSION}

Follicular cholecystitis is very rare gallbladder pathology. A few cases have been published with an occurrence frequency of less than $2 \%$ [6]. It comprises hyperplastic lymphoid follicles with germinal centers consisting of the polymorphic lymphoid population distributed throughout the whole gallbladder wall [7, 8].

Lymphoid hyperplasia can be located in the lungs, orbit, skin and the GIT [2]. The presence of lymphoid tissue in the gallbladder mucosa is extremely rare, and there is a lack of any lymphoid follicles whatsoever. There were intraepithelial lymphocytes located among the superficial epithelial cells [9]. The presumption is that the reactive lymphoid hyperplasia occurs either after a prolonged inflammation or as a result of autoimmune disease [3].

The reactive lymphoid hyperplasia must always be differentiated from malignant lymphoma. 
Frequently they are disguised from cholecystitis. The most common ones are mucosa associated lymphoid tissue (MALT) lymphoma, follicular lymphoma, mantle cell lymphoma and CLL/SLL [10]. MALT lymphoma of the gallbladder is described with diffuse infiltration of cells which resemble small follicular cells and a great number of plasmocytes as well as epithelial invasion of the lymphoid cells. This differentiates it from the reactive changes [11].

Malignant lymphoma is an important differential diagnosis of reactive lymphoid hyperplasia and is always a possibility to be kept in mind although lymphoma is thought to be a primarily tumor of lymph node, a substantial proportion arises from other tissue [10]. Most common lymphoma masquerading as cholecystitis are mucosa associated lymphoid tissue(MALT) lymphoma, follicular lymphoma, mantle cell lymphoma, Chronic lymphocytic leukemia/Small lymphocytic lymphoma (CLL/SLL). The primary MALT lymphoma of gall bladder is characterized by diffuse infiltration of cells resembling the small cleared follicular cells and many plasma cells along with epithelial invasion by lymphoma cells thus differentiating it from reactive changes [11].

Immunohistochemistry detection (IHC) of BCL-2 oncoproteins was shown diffuse and intense positivity in FL, while the normal germinal centers look BCL-2 positivity with less prominence in mantle zone and interfollicular cells [9]. Mantle cell lymphoma consists of small to medium sized centrocyte cells exhibiting CD5 and cyclin D1 positivity, also BCL-2 expression. Chronic lymphocytic leukemia (CLL) with gall bladder involvement is extremely rare on histology a monotonous population of small monoclonal lymphoid cells infiltrating the gall bladder wall is seen. Hence CLL is also a diagnostic possibility. IHC was showed strong positivity for BCL-2, CD5, CD23, CD43, and PAX-5. However our case was negative for CD5 and BCL-2 markers [12].

\section{CONCLUSION}

A rare case of chronic cholecystitis with benign lymphoid hyperplasia and pyloric metaplasia is presented herein. Malignant lymphoma of gallbladder should be eliminated as a possibility for cases with lymphoid hyperplasia. When located in the gallbladder, the cholecystectomy is of curative nature and the prognosis is good. IHC staining tests in the combination of morphology are necessary in order to confirm the diagnosis.

\section{REFERENCES}

1. Albores-Saavedra, J., Gould, E., ManivelRodriguez, C., Angeles-Angeles, A., \& Henson, D. E. (1989). Chronic cholecystitis with lymphoid hyperplasia. Revista de investigacion clinica; organo del Hospital de Enfermedades de la Nutricion, 41(2), 159-164.

2. Machida, T., Takahashi, T., Itoh, T., Hirayama, M., Morita, T., \& Horita, S. (2007). Reactive lymphoid hyperplasia of the liver: a case report and review of literature. World journal of gastroenterology: WJG, 13(40), 5403.

3. Takahashi, H., Sawai, H., Matsuo, Y., Funahashi, H., Satoh, M., Okada, Y., ... \& Manabe, T. (2006). Reactive lymphoid hyperplasia of the liver in a patient with colon cancer: report of two cases. BMC gastroenterology, 6(1), 25.

4. Rana, S., Jairajpuri, Z. S., Khan, S., Hassan, M. J., \& Jetley, S. (2014). Gall bladder lymphoid hyperplasia: Masquerading as lymphoma. Journal of cancer research and therapeutics, 10(3), 749.

5. Singh, M., Vishwakarma, I., Kumar, J., Omhare, A., Mishra, V., \& Verma, Y. N. (2017). Follicular cholecystitis with cholelithiasis: a rare case report. Int. J. Life. Sci. Scienti. Res, 3(5), 14081410 .

6. Mills, S. E. (2015). greenson JK, hornick JL, longacre TA, reuter V E. Surgical histopathology sternberg's, 1781.

7. Hussain, S. A., English, W. E., Lytle, L. H., \& Thomas Jr, D. W. (1976). Pseudolymphoma of the gallbladder. American Journal of Gastroenterology, 65(2).

8. Rosai, J. (2012). Ackerman's surgical pathology Rosai and Ackerman's. 10th ed, 2:988.

9. WANG, T., LASOTA, J., HANAU, C. A., \& MIETTINEN, M. (1995). Bcl-2 oncoprotein is widespread in lymphoid tissue and lymphomas but its differential expression in benign versus malignant follicles and monocytoid B-cell proliferations is of diagnostic value. Apmis, 103(78), 655-662.

10. Dasanu, C. A., Mesologites, T., Homsi, S., Ichim, T. E., \& Alexandrescu, D. T. (2010). Chronic lymphocytic leukemia presenting with cholecystitis-like symptoms and gallbladder wall invasion. Southern medical journal, 103(5), 482484.

11. Ferry, J.A., Harris, N.L. (1997). In Atlas of lymphoid hyperplasia and lymphoma. In: Day L, editor. 1 st ed. Philadelphia, PA: W.B. Saunders Company, 130-2.

12. Doroshow, J. H., Sears, H., Myers, C. E., \& Anderson, T. (1980). Biliary colic heralding systemic relapse in non-hodgkin lymphoma. Journal of surgical oncology, 14(3), 255-259. 